\title{
The Objectifying Gaze: A Lacanian Reading of Viet Thanh Nguyen's The Refugees
}

\author{
Nurfarah Hadira Abdul Hadi ${ }^{a}$ \\ hadirafarah@gmail.com \\ School of Humanities, \\ Universiti Sains Malaysia, Malaysia \\ Moussa Pourya Asl ${ }^{b}$ \\ moussa.pourya@usm.my \\ School of Humanities, \\ Universiti Sains Malaysia, Malaysia
}

\begin{abstract}
With the recent prevalence of white supremacist discourses in the United States, Asian Americans have unavoidably been subjected to xenophobic gazes and tendencies. The white gaze has traditionally enjoyed the privilege to objectify and fix the diasporic subject both racially and ethnically, foregrounding a relationality that naturalizes the immigrant as the inferior subject. The Vietnamese American writer Viet Thanh Nguyen recounts similar unsettling experiences and sufferings of the Vietnamese (refugees) in his debut short story collection The Refugees (2017). This essay seeks to explore the narratives to outline the patterns of looking dynamics and stratified and interracial gaze operating among the characters. To this end, Lacanian theories of the gaze, the jouissance drive and the mirror stage are employed to examine the subtle nuances and complex mechanisms of looking relations that are instrumental in the development of Vietnamese characters. It is easily noticeable that the growing consciousness among the characters of their prescribed inferior position in the scopic order engenders in them feelings of anxiety and/or conflicting sexual impulses, or the jouissance drive. Nonetheless, the hierarchal gaze is not depicted throughout the collection as an essentialized and fixed phenomenon. Rather, some of the Vietnamese characters succeed to control, recodify and reassert the prevailing structural domination of the looking relations, and hence reclaim their agency and subjectivity in relation to the Other. It is concluded that Nguyen successfully upends the dominant discourses of representations in which the Americans' centrality is eternalized while the Vietnamese' is prescribed and nihilated.
\end{abstract}

Keywords: The Refugees; Lacan; gaze; objectification; Vietnamese American

\section{INTRODUCTION}

The victory of Donald Trump in the 2016 presidential election rejuvenated a longstanding white nationalist discourse that has invigorated racial and ethnic resentment in the multicultural social fabric of the United States. Trump's divisive rhetoric both in the course of the presidential campaign and after his rise to power has increasingly exposed the non-white migrant communities to racially xenophobic gazes and tendencies (Abramowitz \& McCoy, 2019; Asl, 2018 \& 2019 \& 2020; Rushin \& Edwards, 2018). Notwithstanding the historical association of Asian Americans ${ }^{1}$ with model minority-i.e., law-abiding and productive immigrants - the "American-ness" of these people have also been subject to the suspecting gaze of American white nationalism. The racializing gaze, or the act of looking per se, is never just an isolated process, but is necessarily a relational dynamic of seeing and being seen, of

${ }^{a}$ Main author

${ }^{b}$ Corresponding author 
looking and being looked at. The white gaze "objectifies" and "fixes" the diasporic subject both racially and ethnically, foregrounding a relationality that naturalizes the immigrant as inferior. As a conceptual term, the hierarchal gaze is therefore as much a tool for engendering and propagating white supremacist discourses as it is for unveiling the destructive and reconstructive impact of objectifying gaze on populations marginalized within such societies.

This essay analyzes the dynamics of the gaze in the Vietnamese American writer Viet Thanh Nguyen's The Refugees (2017), which recounts the agonies and sufferings of the refugees surviving the political repression in Communist Vietnam and enduring a racialized life in America. The collection recommends itself for such a study as patterns of looking dynamics and stratified and interracial gaze formulate the backbone of the stories. The writer's use of a multitude of narrative perspectives underscores the variety of looking positions that the Vietnamese characters have been through due to the dehumanizing effects of the war and repression in their homeland and the hardships of living in diaspora. At a deeper level, however, the workings of the socially embedded hierarchies of gaze among characters as well as their awareness of and participation in such operations unpack the power of looking in the formation of an under-/privileged social identity. Liem of the short story "The Other Man", for instance, is both the object of and a participant in a homosexual gaze. He is subjected to a scopophilic tension that eventually leads him into a homoerotic affair, a dictum that separates him from his former correct and healthy Vietnamese self. The characters of other stories, however, are mainly subjected to the gaze of the Other. For instance, while Phuong of "Fatherland" suffers from being an object of interest for tourists both in her personal and professional life, Thomas of "Someone Else Besides You" is tormented by the gaze of a phantom in his dream. Throughout the stories, no matter how the characters become the object of the gaze, it all comes back to the trauma of the past and the estrangement towards life in a new abode.

Jacques Lacan offers a useful conceptual framework for analyzing the functionings of the looking relations through his theories of "the gaze" and "the mirror stage". At an ontological level, Lacan (1995) clearly distinguishes between the eyes and the gaze. Whereas the former refers to the stares of one person at another, the latter concerns the position of the observer and the observed as well as the relationship between the two poles. Lacan believes that there is an overseer, a gaze that exists outside of one's comfort. Once subjected to this appropriating gaze, the scopic drive will manifest itself in the scopic order because the drive indicates that one is being seen, that there is a gaze casting outside of one's field of vision (Lacan, 1995, p. 139). In this context, Lacan introduces the "mirror stage" which aids the discussion of the gaze through its dehumanizing effect engendered by the reflection of the mirror. The annihilating effect would ultimately butcher the self's initial perception of itself to the point of distortion. Hence, Lacan's conceptualization of the gaze and the mirror stage would be both the act and the tool in the final stage of the subject's development.

A Lacanian study of the hierarchies of looking in The Refugees offers the advantage of unveiling the social and psychological facets of the characters' motivations and growth throughout the collection. The concept of the gaze as a tool to achieve self-actualization is insightful since individual's growth advances once the self realizes that it is not where it wants to be. The awareness of the workings of gaze is predominant among the fictional characters in so far as they suffer from constant anxiety about being watched. Lacan's notion of anxiety unravels the ways in which looking relations between the subject and the object of the gaze throws the latter into a loop of trepidation, leaving it scarred for life. In addition, a Lacanian framework explains how through the realization of the objectifying gaze, the self would expose the hidden drives which in return help in understanding the development of the characters. The Refugees provides numerous instances of the appropriating gaze that provokes anxiety in many of the characters. Thus, Lacanian gaze can be adapted as a framework for examining looking 
relations, objectification or appropriation that creates anxiety along the lines of race, ethnicity and national origin.

In what follows, we will first contextualize Nguyen's The Refugees within the contemporary discourse of Vietnamese American literature and will then proceed to historicize the notion of gaze within this diasporic community. We then aim to delineate the conceptual contours of the gaze from a Lacanian viewpoint by drawing on his notion of the mirror stage. Finally, we explore most of the stories in the light of the different literal and metaphorical implications of the gaze that affect the process of character development in the stories.

\section{REFUGEE WRITING AND CONTESTATION OF THE OBJECTIFYING GAZE}

When looking at the bulk of the Vietnamese American literature produced in the past four decades one is perplexed with the complexities of Vietnamese American identity and politics. At the center of these narratives, there is a collective attempt to re-examine the representations of the Vietnam war and the multi-generational diasporic experiences in America. To understand the thematic terrains of these narratives, a little historical background is useful. After the fall of Saigon and its pro-American South Vietnamese regime to the North Vietnamese communists in 1975, a massive influx of refugees fled across the border to escape state repression and punishment. Those who arrived in America as "waves of unwanted refugees" were soon subjected to an ethnically objectifying and racially humiliating gaze, were commonly labelled as the "boat people," and were immediately objects of suspicion owing to their affiliation with an opponent country. This is understandable from a historical viewpoint as the American society was at the time locked in a long, tense rivalry known as The Cold War (1947-1991) which had brought about growing anti-communist suspicions, and constant surveillance and policing of diasporic individuals and communities - in particular of those connected to a communist land. The persistent monitoring gaze was an added challenge for the "unwanted" Vietnamese refugees in the process of adjusting to their new life in the United States (Eyerman, 2019, p. 159). Individually and collectively, the Vietnamese immigrants employed different discursive strategies - e.g., "through their spoken and written activities, their use of signs and symbols, and their political actions such as protesting, campaigning, and law passing" (Tran, 2020, p, 229) - to show their allegiance to the political and ideological order of the host land. ${ }^{2}$ Even though the community's collaborative efforts for political and cultural incorporation eventually resulted in acceptance of them as good refugees, the trauma of assimilation and the grim legacy of forming a new individual and collective identity after their exodus shape the mainstay of their writings.

Studies on Vietnamese American literature reaffirm the fact that tales of hardship and resilience and their enduring legacy have become the primal scene of the narratives. In her rather comprehensive reading of some canonical works of the community, Pelaud (2011) asserts that trauma and racism form the identities of Vietnamese American characters and narrators. In like manner, Brownlie (2020) argues that parents' traumatic experiences shape the child refugees and later generations' literary and filmic works. As the most prominent writer of the community who won the 2016 Pulitzer Prize for fiction, Viet Thanh Nguyen offers in The Refugees "graphic depictions of the trauma and suffering of the Vietnamese" as refugees (p. 194). The stories have autobiographical input and embody concerns and points of view of its writer as a child refugee who seeks to contest and reform stereotypical perceptions and memories. Of personal accounts of his own experiences of loss and survival in the American soil, Nguyen confides to us how at times his "humanity was temporarily put into question" as a refugee. At the age of four, he was separated from his family, who were kept in a refugee camp in Pennsylvania, to live with a white American family. It was at that time that Nguyen grew conscious of the underlying discourse of white supremacy which indicated "that in the 
United States, land of the fabled American dream, it is un-American to be a refugee" and that the "refugee embodies fear, failure, and flight" (Nguyen, 2017, p. 209).

Critics have widely acceded to the opinion that racial objectification and a life of invisibility and isolation are what binds together all the stories in The Refugees. Several reviews stand out in particular. In her analysis of the stories, Joyce Carol Oates (2017) names Nguyen as "one of our great chroniclers of displacement" whose stories show how the loss of identity that the Vietnamese refugees have had to endure in America has forced them to become "displaced" and "nationless" individuals (para. 2). In this relation, Nguyen and Fung (2017) and Min (2018) acclaim the stories for contesting the dominant objectifying gaze cast on Vietnamese diaspora and challenging the refugee writing discourse that propagates a cliched idea of immigrants as a potential national threat. This is achieved, according to Asaad (2019), through portrayal of a group of characters that reminds us "of how the Vietnamese were once also labeled as refugee" and encountered hostility and racial violence in a country that was responsible for their escape (p. 11). In addition, it shows Nguyen's attempt to rebut racial profiling and hate crimes and to fight for racial justice and equality. In like manner, Wilson (2017) suggests that the common problem of being perceived as "un-American," as generally experienced by the diasporic communities in the United States, is woven into The Refugees ( $\mathrm{p}$. 73). But what differentiates Nguyen from other refugee writers is his non-linear and nonteleological stories that do not romanticize migration as well as his distance from cliched representations of the war.

To an extent, Nguyen's The Refugees does concern with the subjects of power, authority, and position as repercussions of the war. In his review of the stories, Lee (2016) claims that Nguyen's suggestion that the U.S. discourse on international politics was in fact the impetus generating a seemingly positive dominant narrative for the Vietnamese Americans while hiding a stark reality, because many Vietnamese and Southeast Asian Americans are the "subaltern" and the "emblematic victim" of the overriding narrative (p. 232). This viewpoint underlines the existing limited control given to Vietnamese Americans with regards to their fictional writings, and underscores their difficulty in intervening in the common national discourse because of language barrier (August, 2018, p. 66). As refugee accounts strongly accentuate humanitarian failure in the face of state-sanctioned war and state-authorized catastrophe (Schlund-Vials, 2018, p. 6), Nguyen's characters daub a sentiment on the power and authority forced onto them under contentious politics. Sandelind (2020) professes that refugees are exposed to the harm of displacement. As an outcome of the communist (pre)occupation in Vietnam, territorial stability was not guaranteed unless assimilation into the host culture is initiated and this occurrence affects one's own identity root. For that reason, the shorts stories focus on the development of personal identity in the absence of political nations that are otherwise significant in determining rights and privileges of an individual (Perlmutter, 2018, p. 87).

Bosman (2019) refers to Nguyen's own argument that the dominant discourse about the Vietnam war tends to depict Vietnamese refugees as victims, culprits, or revolutionary heroes whilst never saving them a degree of agency and subjectivity to call for the study of Nguyen's narrators and characters not as the object but the subject of an assertive gaze. Much of the existing body of literature, however, is devoted to the study of Nguyen's The Sympathizer (2015) which won him the Pulitzer Prize for Fiction in 2016. Hence the scarcity of research on his The Refugees and the significance of the present reading of Nguyen's stories with a Lacanian analytical tool to explore the operating dynamics of gaze. In general, the looking relations determine the hierarchies of power as who holds the gaze can exploit it to exercise oppression and power. According to Asl (2015), gaze theory is commonly used as a theoretical approach "to help explain the hierarchical networks of power existing between two or more groups or, alternatively, between a group and an object" (p. 92). As victims of war, the 
Vietnamese characters are subjected to a multitude of appropriating gazes that reshape their identities. In what follows, we aim to apply a few variables in Lacanian approach that can affect the process of identity construction.

\section{LACANIAN GAZE: THE JOUISSANCE DRIVE AND THE MIRROR STAGE}

The theoretical approach to the study of The Refugees (2017) is generated from the Lacanian notion of the gaze, the jouissance drive and the mirror stage, and how they are reinforced through the development of the characters who are displaced both in Vietnam and in the United States. Lacan's theory of the gaze is based on the idea that there is a precedent gaze by an imaginary being that makes the subject of the gaze visible in the first place. Lacan explains this as a given-to-be-seen to the seer through which at the initial relationship to the world, something is given-to-be-seen to the seer hence there is a given-to-be-seen before the seen (Lacan, 1995, p. 139). In other words, there is a preexistent gaze that is staring at the subject. This phenomenon draws in the drive that reveals itself in the scopic order because the gaze threatens to unravel all desires through the eruption of the Real (Felluga, 2011). Lacan's concept of the gaze is not associated with the eyes because "the eye viewing the object is on the side of the subject, while the gaze is on the side of the object. When I look at an object, it is always already gazing at me from a point at which I cannot see it" (Žižek, 1993, p. 109). This phenomenon can be both pleasurable and disturbing to the subject.

The drive, also referred to as the jouissance, is articulated through Lacan's reading of Freud's "Instincts and their Vicissitudes," whereby the gaze is presumed to be the object in the scopic drive (Lacan, 1995, p. 140). This means that the gaze is the cause of desire; hence, the drive will return the gaze towards the subject once it is satisfied (p. 141). The manifestation of anxiety is equally possible during the presence of the gaze (p. 144). In other words, not only the gaze may engender a desire in the subject that can expose him/her to gradual evolution, but the realization of the gaze can also create anxiety as a transcendence from the Imaginary and the Symbolic into the Real takes place. According to Felluga (2011), "Lacanian Gaze, [is] the realization that behind our desire is nothing but our lack: the materiality of the Real staring back at us" (para. 3). As an analytical example, this drive can vividly be illustrated by Phuong of "Fatherland" whose desire to be on par with her American half-sister is crushed by the impending truth that her sister's life is not as well as she imagined. Subjection to the objectifying gaze of American tourists produces a desire in Phuong to be like them. The desire, however, turns into a manifestation of anxiety at the revelation of the fact that her sister's display of extravagance is a lie.

Lacan also explained the mirror stage as a concept closely related to the gaze. This stage refers to the phenomena of doubleness when one stares into the mirror but fails to recognize oneself as there is an uncanny feeling of being gazed at when nothing is there (Lacan, 1995, p. 144). The tool for the mirror stage to function does not necessarily have to be a mirror because anything which can reflect the subject's image may trigger the uncanny feeling of being stared at out of nowhere. To understand the mirror stage, one must keep in mind that this concept is an early stage in children's development of identity. It begins during infancy, when the child can recognize its own image in the mirror (Smith, 2010). As a baby, the child is powerless and has no control over its actions and needs. It relies upon its caretaker for the most part of its daily life. However, once it recognizes its own image in the mirror, the child realizes that it does have some sort of control over the image in the mirror. In return, this gives immense pleasure to the gazing child. As much as the image recognition provides narcissistic fulfillment towards itself, the image also has an alienating effect towards the child. Previously, the child only saw itself as separate parts, for example as hands and legs, before it could recognize its own image in the mirror. Now that the child comprehends its reflection in the mirror, it feels 
hostile towards its own image. Homer (2005) explains that "from the moment the image of unity is posited in opposition to the experience of fragmentation, the subject is established as a rival to itself" (p. 26). This sense of rivalry, as he maintains, "is also established in future relations between the subject and others" (p. 26). This means that the hostility will continue throughout the child's lifetime and will affect the way it sees itself or other people around it. On top of being alienated by the mirror image, Lacan draws a possibility of the gaze appearing as a magnified series of multiplying gazes towards the subject. Accordingly, the delusion of being observed is a symptom of paranoia and it is a persecutory delusion develops around the gaze (Lacan, 1995, p. 145). The most compelling evidence of the mirror stage being closely related to the gaze is clearly represented through Liem of "The Other Man" who eventually becomes unable to recognize his own reflection in the mirror and develops a delusion of being gazed at by unknown spectators.

To further elaborate the point, Lacan (1995) draws upon Freud's article titled "The Psychoanalytic View of Psychogenic Disturbance of Vision" to explain the concept of hysterical blindness as a result of sexual scoptophilia, or scopophilia (p. 146). Scoptophilia is an activity of the drive and the gaze that is interlaced with sexual temptation. Often times, the male gaze is the one that is related to this concept by which sexual objectification of the female occurs due to scopophilic tensions or voyuerism (Montebruno, 2003, p. 15). According to Lacan (1995), the result of this tension is an unbearable blindness because the repressed drive takes its vengeance from being held back from further physical coition by dominating other parts of the body to be at its service (p. 146). The effects of scoptophilic blindness is evident in Liem during the aftermath of his love affair for he fails to recognize his own reflection in the window, eventually causing him to lose himself at the end of the story. It is noteworthy that Lacanian gaze does not suggest a relation between seeing and being seen. It mainly is about the presence of uncanny in being looked at by the Other, or the object of one's gaze. As Sharma and Barua (2016) put it, "Lacan stands on a non-reciprocal relation between seeing and seen by making a difference between the eyes of the subject that looks at and the gaze which is on the side of the object without having any capacity to become a subject" (p. 74).

To wrap up, Lacan suggests that there is a pre-existing gaze as a catalyst for the manifestation of the drive and anxiety in the scopic order $(1995$, p. 139). The drive, also referred to as the desire, is divulged by the subject's consciousness of the pre-existing gaze ( $\mathrm{p}$. 139). Satisfying the drive helps the subject in gaining back the dominance over its position as the holder of the gaze. In addition, the presence of gaze and the consequent fear of being judged can generate anxiety (p. 144). The development of both the drive and anxiety compels the subject to work towards satisfying the desire and getting rid of the fear of being watched. Regardless, there are subjects who fail to indulge in the drive and have come to terms with the uneasiness of being observed. On the other hand, there are individuals subjected to the "scoptophilic tension" which has resulted in their exposure to psychosis blindness (p. 146). In certain circumstance, the gaze may come in multiple forms with the aid of a mirror. The mirror image acts as the beholder of the gaze, staring down towards the subject while producing an uncanny feeling. All in all, these are the notions needed in the following analysis of Nguyen's short stories with a Lacanian framework.

Lacan's theory on the notion of gaze and its related conceptions are useful in teasing out the development of the characters in The Refugees and explaining the drives behind their actions. A Lacanian examination of the looking relations in The Refugees unravels the social and personal aspects of the characters' motivations and development. The notion of the gaze as an apparatus to realize self-actualization is helpful because a subject's development progresses only when it notices that it is not where it wants to be. The consciousness about the operations of the gaze is the source of a constant anxiety (Sumali \& Asl, 2019), a feeling that is prevalent among the refugees. A Lacanian understanding of such an anxiety explains how in the 
hierarchy between the subject and the object of the gaze, the latter is thrown into a loop of trepidation. Moreover, a Lacanian perspective demystifies the ways in which the awareness of an objectifying look causes the self to reveal its psychic latent drives. Nguyen's collection portrays several examples of the objectifying gaze that produces anxiety in many of the characters. Therefore, a Lacanian perspective is useful as a framework for analyzing looking mechanisms, objectification or appropriation that instigates anxiety along the lines of race, ethnicity and national origin. In what follows, the study will apply Lacan's theories on the characters of Phuong, Thomas, Mrs. Khanh, Carver, Liem, Marcus and the narrator of the "Black-Eyed Woman."

\section{LOOKING RELATIONS IN THE REFUGEES}

When reading The Refugees one is inundated with various modes of looking relations that prove to be instrumental in the (re-) shaping of the Vietnamese characters either in their homeland or in the United States. One illustrative example of the workings of the gaze takes place in the story titled "Fatherland," where the main protagonist named Phuong evolves from being a passive receiver of a multitude of appropriating gazes to an active owner of assertive eyes. A few lines into the story, we encounter Phuong feeling extremely envious of her sister and namesake, who lives in America under her new name Vivien and is returning to Vietnam to pay them a visit. Phuong, now twenty-three, finds herself the object of her sister's fascination and recalls how throughout her life tourists and customers at her workplace have similarly asked to photograph her, "requests that were initially flattering but now usually irritating" (Nguyen, 2017, p. 186). The gaze of the travelling foreigners objectifies Phuong as representative of Vietnamese people as they assume the Vietnamese "are all the same, ... small, charming, and forgettable," a homogenizing representation that Phuong worries "her sister might see her in this way as well" (p. 193). Phuong's irritation emanates from her realization that the photographs represent more than a slice of Vietnamese life frozen in space and time; they serve as exotic souvenirs that also expose a fracture between Vietnamese and American ways of life. The tourist gaze and photography's multi-temporality are employed in this narrative to the theme of racial difference and intercultural gaze that are so dominant throughout the collection. Furthermore, Phuong's fear of judgment and her anxiety about the pictures is aggravating because of her inability to get the photos back and hence reclaim her dominance over the prevailing gaze. As we are told, "[w] hat she actually looked like she never knew, for while everyone promised to send her the pictures, no one ever did" (p. 186). Besides, the drive that grows in Phuong is her wish to be like her sister Vivien, who is authoritative and far more successful career-wise (p. 185). Phuong yearns for these traits, but she is also jealous of Vivien, a portrayal of the anxiety as a result of being looked at from multiple physical and metaphorical directions (p. 187). At the peak of the anxiety, Vivien's display of her extravagant life is revealed to be a lie and the disclosed hypocrisy of hers shatters Phuong's hopes and dreams. The developed anxiety is further reinforced when Phuong is forced to wear ao dai and be photographed as a departure gift for her sister in the same way that she is subjected to the travellers' gaze (p. 206). Nonetheless, Phuong's final act of burning the photographs of herself taken during Vivien's visit marks the return of the drive towards the subject, simultaneously indicating her exit from being subjected to the gaze surrounding her. Here, the by now unprivileged gaze of Phuong is given the chance to see in the pictures "its own gaze ... [see] 'itself seeing' ...providing the very illusion of perfect self-mirroring” (Žižek, 1993, p. 114). It is at this moment that Nguyen successfully underlines the Vietnamese character's conventional position as neutral and objective observer by paradoxically pinning Phuong to the observed object itself. In this regard, "Fatherland" successfully portrays Lacan's conception of the gaze 
through the development of Phuong as a character subjected to the gaze of the travellers to a one capable of subjectivizing others, and hence in control of the dominating gaze.

The presence of the gaze in relation to the subject's desire and anxiety is also emphasized by Thomas of "Someone Else Besides You." In this story, the workings of the gaze become particularly noticeable during bedtime when Thomas is haunted by something that observes him quietly. As we are told, Thomas is secretly gazed at by something we are not sure of its being. When he finds out about his dead mother's wig that his father has kept in the closet, the readers are given a description of the phantom. Here, Thomas is exposed as the object of a wry and allusive gaze because as he closes his eyes he sees "the head's oval face once again, marked by an arched nose and thin lips, its expression white, blank, and eyeless as it gazed down upon [him]" (Nguyen, 2017, p. 175). The possibility of the piercing gaze coming from his dead mother may, on the one hand, indicate her unsatisfaction in how her picture alone was not put on next to the photographs of his dead grandparents as per custom (p. 155). And on the other, it may be the sign of his inner wishes for the mother-figure as the object of love. From a Lacanian perspective, and influenced by a Freudian Oedipus complex, the attachment of a male subject to the mother, or to a substitute for her, not only is intrinsically normal but it also is typical of a man developing overtly masculine lines. In this example, two distinct images, that of "oneself" and that of the "mother" are identified. Even though at a pre-symbolic world, neither of the images is privileged over the other, the individual must select one over the other upon its entry into the symbolic. In pursuit of his masculine desires, the male figure normally "chooses the image of the mother to fill the place of the 'other', and strives for the desire of the (m)other through 'having' what she lacks-namely, the phallus" (Bristow, 1993, p. 60). Hence, the exposure to the cold gaze of the mother makes Thomas disclose his desire of reuniting with his ex-wife Sam and become the father of the child she is carrying. In other words, Thomas's desire for the mother-figure as the object of love functions as a jouissance drive hence why he was afraid he would mirror his parents' problematic relationship with Sam's unborn child. However, it is important to note that from a Lacanian (1995) perspective a jouissance can be extinguished by articulating something about the jouissance because "when you say it [that is jouissance], you lose a part of it" (p. 106). Therefore, when Thomas verbally offered to be the father to Sam's child, he successfully incapacitated his jouissance (Nguyen, 2017, p. 179). Thomas is also able to overcome his fear of ending up being a bad father-figure like his own father who was very strict towards his sons and unfilial towards his wife. Eventually, the manifestation of his desire and anxiety in the scopic order symbolically come to an end in the scene where he asks to get back together with Sam in the presence of his father (Nguyen, 2017, p. 179).

In another story titled "I'd Love You to Want Me," the female protagonist Mrs. Khanh is simultaneously excluded from her husband's scopic field and disturbed by the fixed gaze of a painting on the wall. On repeated occasions, her husband mistakenly calls her "Yen" which harbours in her heart dark suspicion about his marital commitments. At the same time, the steady gaze directed on her from the Picasso painting brought home by her son discomforts her due to "the way the woman's eyes looked forth from one side of her face" (Nguyen, 2017, p. 107). In Lacanian approach, inanimate items similarly provide the feeling of being objectified. As he explains:

“. ... the gaze is not located just at the level of the eyes. The eyes may very well not appear, they may be masked. The gaze is not necessarily the face of our fellow being, it could just as easily be the window behind which we assume he is lying in wait for us. It is an $\mathrm{x}$, the object when faced with which the subject becomes an object." (Lacan, 1991, p. 220)

In other words, the source of the gaze is not limited to entities with physical eyes, but can be random objects lying around us. In this sense, the painting of a woman in "I' $d$ Love You 
to Want Me" is the entity that pushes Mrs. Khanh to become an object of its gaze. Nguyen (2017) describes the painting as being in "a heavy gilded frame evocative of nineteenth-century Europe" with odd physical structure; one eye green, another eye red, flattened arms and torso akin of pasted cut-outs to a three-dimensional chair (pp. 104-105). The painting makes Mrs. Khanh uneasy as if it seems to be alive and constantly watching her in the confines of her space. The anxiety from being seen prompts Mrs. Khanh to move the painting away into her husband's library and position it to face the wall (p. 107). In Lacanian gaze theory, this state of uneasiness may come from the feeling that the beholder "sees where I am not" (Lacan, 1991, p. 224). In a way, the reason for the agitation behind the painting is connected to the issue of her husband's constant error in addressing her as Yen when her actual name is Sa, thus seeing her for another individual. It drives Mrs. Khanh into a state of confusion about reality because it seems like her memory has been altered, and this phenomenon increasingly alienates her from both her husband and herself. Both the penetrating gaze of the portrait and her husband's unconscious elimination of her from his line of vision distorts Mrs. Khanh's perception of reality. According to Berger (2008), this phenomenon reflects a framework concerning the power of the beholder to a gaze between men and women. Because within a heterocentric framework of the real world, "men look at women. Women watch themselves being looked at. This determines not only most relations between men and women but also the relation of women to themselves. The surveyor of woman in herself is male: the surveyed female" (Berger, 2008, p. 4). That is why Mrs. Khanh's alienation becomes visible as she sees herself not being seen, and hence she doubts her own identity either as Mrs. Khanh the wife or as Yen the name Mr. Khanh dubbed her when his illness developed (Nguyen, 2017, p. 99). However, she gradually overcomes the feeling as she realises that her attitude reflects her presence in the sense that what can or cannot be done to her depends on her very own presence that she expresses. In consequence, she decides to get the painting reframed as a signature of breakthrough from her drive and anxiety (p. 124). This scene proves to be the most poignant moment in the operation of the gaze in the story as she finally succumbs to being called Yen because of her love towards her husband that defeats the anxiety of being alienated by herself.

In certain circumstances of looking operations, however, the drive does not return to the subject due to the unsuccessful satisfaction of the desire exhibited by the gaze. Two prime examples are illustrated by Carver of "The Americans" and the narrator of "Black-Eyed Woman" who are unable to control the gaze directed towards them and remain the target of several gazes from the mirror image and the unknown onlookers. In other words, the two characters' failure in recodifying the prevailing dominance over the privileged owners of the gaze retains for them an inferior position in the existing scopic order. In the case of Carver, his occupation as a soldier and his marital life with a Japanese woman are the cause of the mocking gaze fixed on his family because they are labelled as a "mixed bag" (Nguyen, 2017, p. 131). Carver is not able to yield to his drive when his anxiety continues to manifest throughout the story as "he was never where he was supposed to be. He had survived by focusing on his goal, ascending even higher, refusing to see the sneers and doubt in his peripheral vision" (p. 132). He always restrains himself whenever he encounters with the objectifying look in peoples' eyes. Besides, Carver's family fail to form their identity, which is crucial to fit in a society, and continue to suffer the menace of the Other's gaze. Carver's failure in reshaping his identity thus demonstrates the inability of his drive to return to him while also suggesting his failure in controlling the others' gaze. In like manner, the Vietnamese narrator of the "Black-Eyed Woman" is unable to control the gaze of the Other. Notwithstanding, she is able to make peace with her anxiety. All her life, the narrator seeks to avoid potentially dangerous situations owing to the traumatic memories of several deaths that occurred around her (p. 7). As a survivor of the war, she is constantly subjected to the gaze of a multitude of ghosts including that of her brother's. As she tells us, the brother's "eyes stared at me whenever I closed my own" (p. 5). 
The scornful gaze coming from the ghosts is discomforting and reveals her hidden anxiety of being actually dead inside (p. 16). However, she is finally able to come to terms with her anxiety by letting go of her guilt towards her dead brother and starting to hunt "for the ghosts" and "seeking them out" in order to write real stories of the Vietnamese refugees (pp. 20-21).

The story titled "The Other Man" portrays through its central character both individual and collective modes of objectifying gaze. At the level of individual, Liem's encounter with a white male portrays a sexual aspect of looking hierarchy, one that engenders and reinforces in him scopophilic tensions. Whereas, at the level of collective objectification, Liem finds himself entangled in the inspecting, controlling, and regulating gaze of the mainstream culture. Even though the story begins with an illustrative example of the latter-i.e., when the crowd make him feel hesitant and anxious - very soon both modes of objectification become intertwined in so far as Liem finds his involvement in scopopilic desires as the influence of the dominant culture. As soon as he arrives in San Francisco, Liem encounters with the confusing "American etiquette" and the discomforting gaze of the Other. This is graphically demonstrated through his American sponsor Parrish Coyne when he picks up Liem at the airport. As soon as he meets Liem,

Parrish unexpectedly hugged him, leaving him to pat the man's shoulder awkwardly, aware of other people watching them and wondering, no doubt, about their relationship. Then Parrish stepped back and gripped his shoulders, staring at him with an intensity that made Liem selfconscious, unused as he was to being the object of such scrutiny [italics our emphasis]

(Nguyen, 2017, p. 24)

Liem's immediate anxiety about the sexual and racial objectification of his body by a male gaze is further aggravated with Parrish's complimenting comment that says, "I didn't expect you to be so pretty' (p. 24). This encounter sets it clear that for Liem to be considered as "liberal" and "open-minded", hence "American", he has to abide by the existing behavioural norms practiced by his sponsors in America.

Another illustrative occasion wherein the gaze of the Other provokes Liem's anxiety is when he finds himself as the object of Parrish's partner Marcus's gaze, which progresses from an initially inspecting one towards a scopophilic gaze and homosexual desire. Liem's awareness of the gaze and his subsequent self-consciousness which were drawn at the airport and then by Parrish, are further heightened by Marcus whose curious stare at Liem in the rear view mirror send "a nervous tremor through his gut" (Nguyen, 2017, p. 28). As the narrative develops, Liem becomes an object of desire to Marcus, a desire for spontaneous entertainment, something that his current partner Parrish has failed to provide. Though at first even the thought of a male couple is unfathomable to Liem and stiffens "[t]he small hairs on his arm and the back of his neck" (p. 28), Liem later accepts this behaviour as part of the mainstream culture. In an act of incorporation to the dominant scopic field, in particular Marcus's scoptophilic gaze, Liem works hard to look good. As we are told, when "Marcus was watching him expectantly.... the desire to appear noble in Marcus's eyes, and maybe his own, seized him" (p. 39). Liem's behaviour in this scene is explainable through the desire of exhibitionism which from a Lacanian perspective is traditionally associated with female body or women who normally position themselves as objects of the desire of a male other. Yet the requirement of a homosexual desire "can only be satisfied in an inexhaustible captation of the desire of the other" (as cited in Bristow, 1993, p. 58). In other words, unlike the female narcissistic desire, the homosexual exhausts "himself in pursuing the desire of the other, which he will never be able to grasp as his own desire, because his own desire is the desire of the other" (p. 58), and this will make it difficult for him to obtain the symbolic anchor of love or the heterosexual exchange. 
The complex nuances of the scopophilic tensions finally create in Liem a hysterical blindness in such a way that he eventually fails to recognize his own reflection in the window. "Why, then," as the narrator asks at the end of the story, "did he not recognize himself?" (Nguyen, 2017, p. 46). Liem's active involvement in the process of self-recreation through his relationship with Marcus is after all built on his erroneous assumption that his engagement in the homoerotic scopic field is crucial for a desirable constitution of the refugee subject in the new land. Therefore, Liem's different looking positions in the story demonstrate how the reflection of one's image can simultaneously be the source of narcissism and self-alienation, and in doing so they underscore the intertwinement of the gaze with the presence of the mirror stage. Liem is both alienated and discomforted by his own reflection at the "mirror image" of the room's bay window, a reflection that he fails to recognize as himself (p. 46). He perceives the reflection as the subject of the gaze cast on him just like the objectifying gaze of the people around him that he has failed to assimilate with. Liem's fear of being the object of the Others' gaze and their judgement continues to exist at the end of the story as he ponders how his figure looks to the passers-by outside the window and wonders "if someone, behind blinds and curtains, might be watching" (p. 47). The increasing fear of being constantly visible to an unknown observer exacerbates his growing sense of alienation from himself and his family, who want him to have a "healthy, correct life" [italics original] (p. 46).

\section{CONCLUSION}

This study employed a Lacanian framework to examine the subtle nuances and complex mechanisms of looking relationality that are instrumental in the development of Vietnamese characters as portrayed in Viet Thanh Nguyen's The Refugees. Six out of the eight stories are directly concerned with dynamics of the gaze in both literal and metaphoric ways. On different occasions, the central characters of the stories - that is, Phuong of "Fatherland," Thomas of "Someone Else Besides You," Mrs. Khanh of "I'd Love You to Want Me," Carver of "The Americans," the narrator of "Black-Eyed Woman," and Liem of "The Other Man"-find themselves subjected to the appropriating gaze of the Other. The growing consciousness among the Vietnamese characters of the hierarchies of the gaze and of their prescribed inferior position in this scopic order in relation to white Americans engenders in them feelings of anxiety and/or conflicting sexual impulses, or the jouissance drive. The looking relationality, however, is not portrayed throughout the collection as an essentialized and fixed phenomenon. Rather, some of the Vietnamese characters succeed to control, recodify and reassert the prevailing structural domination of the looking relations in America. This is particularly true when the characters are positioned under the appropriating eyes of the Americans, a situation in which the self realizes it is not where it wants to be. Phuong, Thomas and Mrs. Khanh perfectly illustrate this point as they succeed to return the drive while reclaiming the dominance over the conventionally privileged owner of the gaze. Here, the nexus between Vietnamese and American sets out a paradigmatic hierarchical relation between the two that is contested, challenged and even inverted: While the Americans are portrayed to be traditionally privileged with the right to look, the Vietnamese (refugees) are stereotypically identified with neutral passivity and objectivity.

Through these characters, Nguyen successfully upends the binary system in which the Americans' centrality is eternalized and the Vietnamese' is prescribed and nihilated. Notwithstanding, both the narrator of the "Black-Eyed Women" and Carver are not able to satisfy their drive. Hence their attempt to control the gaze is thwarted, and they remain to be subjected to the gaze of the other. In any case, the examples underline the political significance of the privilege to appropriate the gaze whereby the existing structural domination in the operating hierarchies of the gaze control the realms of desire. This latter point is more clearly 
and strongly illustrated by the male refugee character Liem who is depicted as the vulnerable target of scopophilic desires of another man in America. In this relation, and in accordance with the homogenizing and homosexual discourse of the dominant culture, the right to look is implicitly denied to the "un-American" refugee. Hence, the Vietnamese migrant character's inactive observation and his scopic identification with the sexual hierarchies of the mainstream position him as a passive spectator who is doubly-i.e., racially and sexually-objectified and alienated. His spectatorship is further complicated as he becomes the victim of multiple gazes from the mirror image and the unknown spectators. Together, all the different kinds of looking relations and scoptophilic tensions eventually result in the refugee character's blindness towards self-identification in the host land. This is understandable through a Lacanian perspective which underlines how the repressed aspects of subjectivity engenders alienation from itself. In this manner, Nguyen's collection of short stories fits into the Lacanian model of the gaze as a tool for self-actualization as shown in the different ways of the development of the Vietnamese (refugee) characters.

\section{END NOTES}

\footnotetext{
${ }^{1}$ According to the Office of Management and Budget, being of Asian descent is defined as any "person having origins in any of the original peoples of the Far East, Southeast Asia, or the Indian subcontinent" (Hoeffel, Rastogi, Kim, \& Hasan, 2012).

${ }^{2}$ The Vietnamese refugees struggle to culturally and politically incorporate themselves finally led them be examples of "good refugees". As an example of their allegiance, in the 1980s, "President Reagan enjoyed much of the Vietnamese American support due to his fight against communism" (Huang, 2017, p. 8).
}

\section{REFERENCES}

Abramowitz, A., \& McCoy, J. (2019). United States: Racial resentment, negative partisanship, and polarization in Trump's America. The ANNALS of the American Academy of Political and Social Science, 681(1), 137-156.

Asaad, L. (2019). Literature with a white helmet: The textual-corporeality of being, becoming, and representing refugees ( $\mathrm{PhD}$ dissertation). The United States: Middle Tennessee State University.

Asl, M. P. (2015). The metaphor of vision and the construction of sexist-norms in Western metaphysics. The Journal of Applied Linguistics and Applied Literature: Dynamics and Advances, 3(2), 91-111. doi:10.22049/jalda.2015.13699

Asl, M. P. (2018). Practices of counter-conduct as a mode of resistance in Middle East women's life writings. 3L: Language, Linguistics, Literature ${ }^{\circledR}$. 24(2), 195-205. doi:10.17576/3L-2018-2402-15

Asl, M. P. (2019). Leisure as a space of political practice in Middle East women life writings. GEMA Online ${ }^{\circledR}$ Journal of Language Studies, 19(3), 43-56. doi:10.17576/gema-20191903-03

Asl, M. P. (2020). The politics of space: Vietnam as a communist heterotopia in Viet Thanh Nguyen's The Refugees. 3L: Language, Linguistics, Literature ${ }^{\circledR}, 26(1), 156-170$. doi:10.17576/3L-2020-2601-11

August, T. K. (2018). Spies like us: A professor undercover in the literary marketplace. Lit: Literature Interpretation Theory, 29(1), 60-79, doi: 10.1080/10436928.2018.1416252

Berger, J. (2008). Ways of seeing (Ch. 1). London: BBC \& Penguin.

Bosman, S. J. (2019). Nguyen's ghosts in The Sympathizer: Collapsing binaries and signalling just memory, Scrutiny2, 24(1), 3-12. doi:10.1080/18125441.2019.1650818 
Bristow, J. (1993). Activating theory: Lesbian, gay, bisexual politics. London: Lawrence \& Wishart Ltd.

Brownlie S. (2020) Facet G: Memory, art and the Vietnamese diaspora. In Discourses of memory and refugees [pp.189-215]. Palgrave Macmillan Memory Studies. Palgrave Macmillan, Cham. doi:10.1007/978-3-030-34379-8_8

Eyerman R. (2019) Cultural trauma, collective memory, and the Vietnam War. In Memory, trauma, and identity [pp. 143-165]. Cultural Sociology. Palgrave Macmillan, Cham. doi: 10.1007/978-3-030-13507-2 7

Felluga, D. (2011). Modules on Lacan: On the gaze. The United States: Purdue University. https://cla.purdue.edu/academic/english/theory/psychoanalysis/lacangaze.html

Hoeffel, E. M., Rastogi, S., Kim, M. O., \& Hasan, S. (2012). The Asian population: 2010. US Department of Commerce, Economics and Statistics Administration, US Census Bureau.

Homer, S. (2005). Jacques Lacan. New York: Routledge.

Huang, C. H. (2017). Disillusionment and disaggregation: Why did Asian Americans vote for Trump? (Senior thesis). The United States: Claremont McKenna College

Lacan, J. (1991). The Seminar of Jacques Lacan, Book I (A. Miller Ed.). (J. Forrester, Trans.). New York: W.W norton and Company.

Lacan. J. (1995). Reading seminar XI: Lacan's four fundamental concepts of psychoanalysis (Richard, F., Fink, B., \& Jaanus, M., Eds.). The United States: State University of New York Press.

Lee, D. M. (2016). A review of youth gangs, racism, and schooling: Vietnamese American youth in a postcolonial context. Multicultural Perspectives, 18(4), 230-233. doi: $10.1080 / 15210960.2016 .1228347$

Min, H. S. (2018). Viet Thanh Nguyen and the scholar; Public intellectual. PMLA, 133(2), 406-412. doi:10.1632/pmla.2018.133.2.406

Montebruno, G. R. (2003). Gazing subjects, gazing objects; Reconfiguring the gaze in Kawabata Yasunari's Novels, 1939-1962 (PhD dissertation). The United States: University of Southern California

Nguyen, M., \& Fung, C. (2017). On writing, radicalism, and literary value: An interview with Viet Thanh Nguyen. Melus, 42(3), 201-221. doi:10.1093/melus/mlx051

Nguyen, V. T. (2017). The Refugees. London, UK: Crosair.

Oates, J. C. (2017, February 13). Refugees in America. The New Yorker. Retrieved from https://www.newyorker.com/magazine/2017/02/13/refugees-in-america

Pelaud, I. T. (2011). This is all I choose to tell: History and hybridity in Vietnamese American literature. Philadelphia: Temple University Press.

Perlmutter, R. (2018). Interview with Viet Thanh Nguyen. Lit: Literature Interpretation Theory, 29(1), 80-89, doi: 10.1080/10436928.2018.1416254

Rushin, S. \& Edwards, G. S. (2018). The effect of President Trump's election on hate crimes. (January 14, 2018). Available at SSRN: https://ssrn.com/abstract=3102652 or $10.2139 / \mathrm{ssrn} .3102652$.

Sandelind, C. (2020). Refugees, displacement and territorial stability. Journal of Global Ethics. doi: $10.1080 / 17449626.2020 .1784250$

Schlund-Vials, C. J. (2018). Raising the dead: The state and stakes of refugee authorship. Lit: Literature Interpretation Theory, 29(1), 1-7, doi: 10.1080/10436928.2018.1415572

Sharma, P., \& Barua, A. (2016). Analysing Gaze in Terms of Subjective and Objective Interpretation: Sartre and Lacan. Human Studies, 40(1), 61-75. doi:10.1007/s10746016-9406-4 
Smith, E.S. (2010). The presence of Jacques Lacan's mirror stage and gaze in Robert Louis Stevenson's Strange Case of Dr. Jekyll and Mr. Hyde and in Rouben Mamoulian's 1931 Film (Master's thesis). The United States: Georgia State University

Sumali, N. A., \& Asl, M. P. (2019). Creating spaces of fear and anxiety: Analysis of factors affecting male character's conduct in Vladimir Nabokov's Lolita. International Journal of Innovation, Creativity and Change, 10(2), 32-43.

Tran, L. T. H. (2020). "Outsiders No More?": The discourse of political incorporation of Vietnamese refugees in the United States (1975-2020). Journal of Asian American Studies, 23(2), 229-264. doi:10.1353/jaas.2020.0019

Wilson, R. C. (2017). Constructed borders and conditional belonging: Refugee narratives in literature and law (Honor's degree). The United States: Macalester College

Žižek, S. (1993). Looking awry: An introduction to Jacques Lacan through popular culture. Cambridge, MA: MIT press.

\begin{abstract}
ABOUT THE AUTHORS
Nurfarah Hadira Binti Abdul Hadi is a student of literary studies at School of Humanities, Universiti Sains Malaysia and her research interests are in South (East) Asian diasporic literature, gender and cultural studies.

Moussa Pourya Asl is a Senior Lecturer in literary studies at Universiti Sains Malaysia, where he also obtained his $\mathrm{PhD}$ (English Literature) from School of Humanities. His primary research area is in diasporic literature and gender and cultural studies, and he has published several articles in the above-mentioned areas.
\end{abstract}

